\title{
Effect of Lutein on Cytochrome P450 (Isoform CYP3A4) - An in vitro Study
}

\author{
Murthy Meenapriya ${ }^{1}$, Roy Anitha ${ }^{2 *}$, Thangavelu Lakshmi ${ }^{2}$
}

\section{Murthy Meenapriya', Roy Anitha' ${ }^{2}$, Thangavelu Lakshmi ${ }^{2}$}

\section{'Graduate Student, Saveetha Dental College, Saveetha Institute of Medical and Technical Sciences, Saveetha University, Velappanchavadi, Chennai, Tamil Nadu, INDIA. \\ ${ }^{2}$ Department of Pharmacology, Saveetha Dental College, Saveetha Institute of Medical and Technical Sciences, Saveetha University, Velap- panchavadi, Chennai, Tamil Nadu, INDIA.}

\section{Correspondence}

Dr. Anitha Roy Associate Professor, Department of Pharmacology, Saveetha Dental College, Saveetha Institute of Medical and Technical Sciences, Saveetha University, Velappanchavadi, Chennai, Tamil Nadu, INDIA.

Phone no: +91-9840787458

Email: anitharoy2015@gmail.com History

- Submission Date: 12-03-2018;

- Review completed: 29-05-2018;

- Accepted Date: 11-07-2018.

\section{DOI : 10.5530/pj.2018.6.185}

\section{Article Available online}

http://www.phcogj.com/v10/i6

\section{Copyright}

(C) 2018 Phcog.Net. This is an open-access article distributed under the terms of the Creative Commons Attribution 4.0 International license.

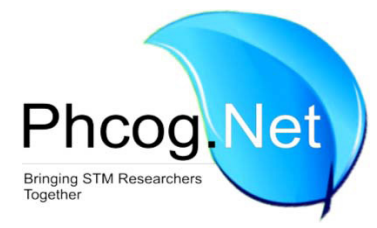

\begin{abstract}
Background: Lutein is a carotenoids vitamin rich in many fruits and vegetables and also available in multivitamin products. It is consumed for its effect on eye disease, cancer, diabetes and other health conditions. Recently, herbal preparations are increasingly used in healthcare systems and concomitant administration of synthetic medications may cause pharmacokinetic or pharmacodynamic interactions leading to very serious medical problems. Understanding the ability of herbal extracts and preparations to modulate the metabolizing enzymes can help the health system for proper treatment of patients and thereby can avoid many adverse effects associated with it. The aim of the study was to find the effect of lutein isolated from Tagetes erecta $L$ on cytochrome P450 isoform CYP3A4. Materials and Methods: The different concentrations of lutein $(5-100 \mu \mathrm{g} / \mathrm{ml})$, potassium phosphate buffer, CYP450 reagent and substrate 7-Benzyloxy-4-trifluoromethylcoumarin (BFC) were added to a 96-well plate. The fluorescent intensities of the products were measured by Perkin Elmer Enspire fluorescence reader using an excitation and emission wavelength of $405 \mathrm{~nm}$ and $460 \mathrm{~nm}$, respectively to examine the effect of lutein on Cytochrome P 450 isoform CYP3A4 and the $I_{50}$ was calculated by plotting concentrations of lutein against the corresponding percent inhibition. Results: All the tested concentrations of lutein showed potent inhibition against CYP3A4 in a dose - dependent manner. The $\mathrm{IC}_{50}$ value was found to be $35.27 \mu \mathrm{g} / \mathrm{ml}$. Conclusion: The inhibitory effect of lutein indicates the possibilities of herb-drug interaction if it is co - administered with prescribed drugs that are normally metabolised by CYP3A4 enzyme.

Key words: Lutein, Cytochrome P450, Inhibitory assay, Marigold, CYP3A4.
\end{abstract}

\section{INTRODUCTION}

Lutein from Tagetes erecta $L$. is a purified extract obtained from marigold, which is extracted from the petals of marigold flowers. Lutein is chemically $3 R, 3^{\prime} R, 6^{\prime} R-\beta \varepsilon$-carotene-3,3'-diol, which is a member of a group of pigments known as xanthophyll. It is used as a food colouring agent and nutrient supplement in a wide range of baked goods and baking mixes, beverages and beverage bases, breakfast cereals, chewing gum, dairy product analogs, egg products, fats and oils, frozen dairy desserts and mixes, gravies and sauces, soft and hard candy, infant and toddler foods, milk products, processed fruits and fruit juices, soups and soup mixes in levels ranging from 2 to $330 \mathrm{mg} / \mathrm{kg}$. ${ }^{1}$ Marigold flower (Tagetes erecta L. Family Compositae) represents a rich source of lutein. It is grown for business purposes in Mexico, Peru, Ecuador, Spain, India or China. Dried Marigold flowers contain 0.1-0.2\% dry matter of carotenoids, out of which $80 \%$ are lutein diesters. By the extraction of dried and ground flowers, a non-polar oleoresin extract is acquired. ${ }^{2}$ The recent evidence suggests that lutein is one of the abundant carotenoids in the diet and it possesses strong antioxidant capacity and may be useful in reduction of incidence of cancer. ${ }^{3}$

The xanthophylls, a major group of carotenoids, primarily include astaxanthin, b-cryptoxanthin, canthaxanthin, lutein, and zeaxanthin. ${ }^{4}$ Unpredicted drug interactions have led to severe adverse effects or treatment failures. Many of these interactions involve the inhibition or induction of drug-metabolising cytochrome P450 (CYP) enzymes. Similarly, dietary supplements or nutrients may be inhibitors or inducers of CYP enzymes and influence the pharmacokinetics of any co-administered drugs. There are few reports about interactions between drugmetabolising enzymes and astaxanthin, b-cryptoxanthin, canthaxanthin, lutein, and zeaxanthin. ${ }^{5}$ the aim of the present study was to find the effect of lutein isolated from Tagetes erecta $\mathrm{L}$ on cytochrome P450 isoform CYP3A4. 


\section{MATERIALS AND METHODS}

\section{Chemicals and Extract}

Potassium phosphate buffer, CYP450 reagent, 7-Benzyloxy-4-trifluoromethylcoumarin (BFC), Tris- $\mathrm{HCl}$ buffer. All the chemicals used were of analytical grade. Lutein extract was obtained from Synthite Industries Limited as gratis.

5-100 microgram concentrations of lutein, potassium phosphate buffer, CYP450reagent and substrate 7-Benzyloxy-4-trifluoromethylcoumarin (BFC) were added to a 96-well plate. The mixtures were pre - incubated for $20 \mathrm{~min}$ at room temperature. The reaction was started by a mixture of reconstituted substrate and $\mathrm{NADP}+$ and incubated at room temperature for 30-60 min. The reaction was stopped by Tris- $\mathrm{HCl}$ buffer, $\mathrm{pH} 10.5$. The fluorescent intensities of the products were measured by Perkin Elmer Enspire fluorescence reader using an excitation and emission wavelength of $405 \mathrm{~nm}$ and $460 \mathrm{~nm}$, respectively. ${ }^{6} \mathrm{IC}_{50}$ was calculated by plotting concentrations of lutein against the corresponding percent inhibition. All tests were done in triplicate and values were expressed as mean \pm SEM.

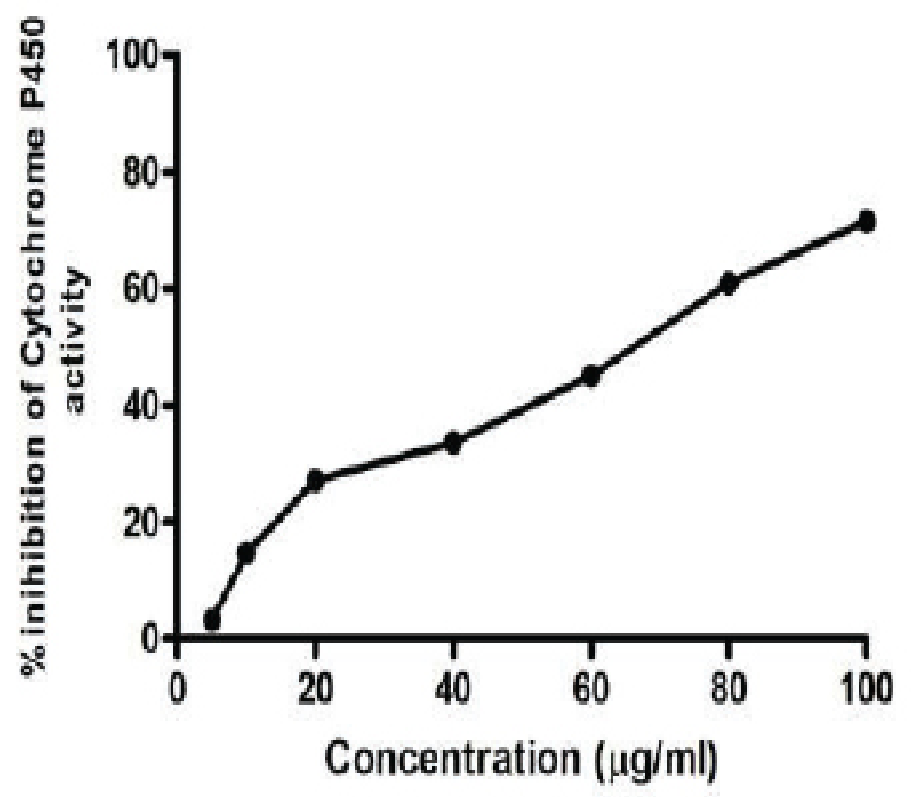

Figure 1: Inhibitory effect of Lutein on Cytochrome P450 Activity.

Table 1: Inhibitory effect of Lutein on Cytochrome P450 Activity.

\begin{tabular}{cc}
\hline Lutein concentration $(\mu \mathrm{g} / \mathrm{ml})$ & CYP450 inhibitory effect $(\%)$ \\
\hline 5 & $3.27 \pm 0.69$ \\
10 & $14.83 \pm 4.16$ \\
20 & $27.24 \pm 0.16$ \\
40 & $33.71 \pm 0.16$ \\
60 & $45.07 \pm 1.17$ \\
80 & $60.95 \pm 0.49$ \\
100 & $71.54 \pm 0.49$ \\
\hline
\end{tabular}

\section{RESULTS}

All the tested concentrations $(5-100 \mu \mathrm{g} / \mathrm{ml})$ of lutein showed good inhibition against CYP3A4 ( Table 1 ,Figure1). The $\mathrm{IC}_{50}$ value of lutein for CYP3A4 inhibitory activity was found to be $35.27 \mu \mathrm{g} / \mathrm{ml}$.

\section{DISCUSSION}

In the present study, lutein extracted from marigold has demonstrated good inhibitory effect on CYP3A4. Results indicate the possibilities of herb-drug interaction if lutein is co-administered with the prescribed drugs that are metabolized by CYP3A4. Lutein is known for its antioxidant activity. ${ }^{7}$

The cytochrome P450 enzymes are the main players in Phase I metabolism and also involved in the oxidation and elimination of a wide array of xenobiotics such as drugs and toxins. ${ }^{8}$ A number of therapeutic agents such as quinidine, vinblastine, ergotamine, berberine, and colchicines synthetic agents such as nifedipine and diazepamare the main substrates of CYP3A4. ${ }^{9}{ }^{10}$ Many plant extracts are capable of inhibiting CYP3A4 activity. ${ }^{11,12}$ Grapefruit and kava-kava are best examples for herbal drugs that can cause clinically important modulation in CYP3A4 activity. ${ }^{13,14}$ Many other plants are also evaluated for their effect on CYP450 enzymes. The effect of $P$. amarus and $P$. emblica aqueous extracts on all CYP isoforms were weaker. In a previous study, extract of Centenella asiatica showed concentration-dependent inhibitory effect on CYP3A4 activities. ${ }^{15}$ Studies show that plant products such as asiaticoside and madecassoside have inhibitory effect on CYP3A4. Asiaticoside inhibited CYP3A4 with an $\mathrm{IC}_{50}$ value of $343.35 \pm 29.35 \mu$ M.Madecassoside, inhibited CYP3A4 with $\mathrm{IC}_{50}=453.32 \pm 39.33 \mu$ M.Asiaticoside exhibited non-competitive inhibition of CYP3A4 Madecassoside also showed non-competitive inhibition of CYP3A4. ${ }^{16}$

The inhibition of cytochrome $\mathrm{P} 450$ metabolism by blended herbal products and vitamins has revealed that the extracts have a low to moderate capacity to inhibit the cytochrome metabolism. ${ }^{17}$ Similarly, studies on Cocktail inhibition assays for assessing the drug-drug, drug-botanical interactions and assessing the six major cytochrome P450 enzymes was conducted by Guannan and Jing Wan respectively. ${ }^{18,19}$

Drug-drug interactions may be identified during drug development and approval, food-drug interaction and supplements-drug interaction should not be overlooked. Natural health products are being widely used. Many plant products are useful in diabetes mellitus, anxiety, cancer and many such health problems. ${ }^{20-23}$ Apart from an appraisal of product safety and effectiveness, attention should be paid to the potential that these product ingredients may interact with medications. In recent years, dietary carotenoids, especially xanthophylls, have attracted significant attention because of their activities as antioxidants and their roles in preventing cancer and age-related macular degeneration. Although around 40 carotenoids are ingested through a typical diet, only a few xanthophylls have been found in human tissues. There are few reports of inducible effects on CYP activities by the xanthophylls astaxanthin, b-cryptoxanthin, canthaxanthin,lutein, and zeaxanthin. However, their inhibitory effects on CYPs have rarely been investigated. ${ }^{5}$

\section{CONCLUSION}

Lutein obtained from marigold petals is of major commercial interest because of its use in functional food and cosmetics, as well as in pharmaceuticals. In conclusion, lutein extracted from Marigold exhibited a dose dependent inhibitory effect on CYP3A4. Results from this study provide information indicating the possibilities of herb-drug interaction if this extract is co-administered with the prescribed drugs that are metabo- 
lized by CYP3A4. Further in vivo study is needed to investigate whether these effects are clinically significant.

\section{ACKNOWLEDGEMENT}

The authors thank Synthite Industries Limited, Kerala for providing the extract as a gift sample for carrying out this project. Also express their gratitude to Ms R. Parameswari, Senior Resarch Fellow, SRMC, Porur, Chennai, for interpreting the results.

\section{CONFLICT OF INTEREST}

Nil

\section{ABBREVIATIONS}

JECFA - The Joint FAO/WHO Expert Committee on Food Additives RSC - Royal Society of Chemistry

\section{REFERENCES}

1. Cantrill R. Lutein from Tagetes erecta.Chemical and Technical Assessment (CTA). FAO. 2004. 63 ${ }^{\text {rd }}$ The Joint FAOMHO Expert Committee on Food Additives(JECFA).

2. Šivel M, Kráčmar S, Fišera M, Klejdus B, Kubáň V. Lutein Content in Marigold Flower(Tagetes erecta L.) Concentrates used for production of food supplements. Czech J Food Sci. 2014; 33:521-5.

3. Khachik F, Beltsville MD. Process for Isolation, Purification, And Recrystallization of Lutein from Saponified Marigold Oleoresin and uses thereof. US Patent.1995.

4. Khachik F, Beltsville, Md. Process for Extraction and Purification of Lutein, Zeaxanthin and Rare Carotenoids from Marigold flowers and plants. US Patent. 2001.

5. Zheng YF, Bae SH, Kwon MJ, Park JB, Choi HD, Shin WG, et al. Inhibitory effects of astaxanthin, Beta-cryptoxanthin, canthaxanthin, lutein, and zeaxanthin on cytochrome P450 enzyme activities. Food and Chemical Toxicology. 2013; 59:78-85.

6. Anannarukan N, Niwattisaiwong N, Warisnoicharoen W, Winitthana T, Pramyothin $\mathrm{P}$, Chaichantipyuth $\mathrm{C}$, et al. Inhibition of human cytochrome P450 in vitro by Phyllanthus amarus and Phyllanthus emblica aqueous extracts. Thai J Pharm Sci. 2012; 36:135-43.

7. Ingkasupart P, Manochai B, Song WT, Hong JH. Antioxidant activities and lutein content of 11 marigold cultivars (Tagetes spp.) grown in Thailand. Food Sci. Technol Campinas. 2015; 35:380-5.

8. Ashour ML, Youssef FS, Gad HA, Wink M. Inhibition of Cytochrome P450 (CYP3A4) Activity by Extracts from 57 Plants Used in Traditional Chinese Medicine (TCM). Pharmacogn Mag.2017; 13:300-8.

9. Wink M. Molecular modes of action of cytotoxic alkaloids: From DNA intercalation, spindle poisoning, topoisomerase inhibition to apoptosis and multiple drug resistance. In: Cordell GA, editor. The alkaloids: chemistry and biology. California, London: Academic Press. 2007;64:1-47.

10. Ioannides C. Cytochromes P450: Role in the metabolism and toxicity of drugs and other xenobiotics. Issues in toxicology. Cambridge: Royal Society of Chemistry( RSC) Pub. 2008.

11. Usia T, Watabe T, Kadota S, Tezuka Y. Potent CYP3A4 inhibitory constituents ofPiper cubeba.J Nat Prod.2005; 68:64-8.

12. Tsukamoto $S$, Aburatani M, Yoshida T, Yamashita Y, El-Beih AA, Ohta T. CYP3A4 inhibitors isolated from licorice. Biol Pharm Bull. 2005;28:2000-2.

13. Ho PC, Saville DJ, Wanwimolruk S. Inhibition of human CYP3A4 activity by grapefruit flavonoids, furanocoumarins and related compounds. J Pharm Sci. $2001 ; 4: 217-27$.

14. Mathews JM, Etheridge AS, Black SR. Inhibition of human cytochrome P450 activities by kava extract and kavalactones. Drug Metab Dispos. 2002;30:1153-7.

15. Seeka P, Niwattisaiwong N, Warisnoicharoen W, Winitthana T, Tantisira MH, Lawanprasert S. Effects of the standardised extract of Centella asiatica ECa233 on human cytochrome P450. Thai J Pharm Sci.2012;36:30-7.

16. Winitthana $T$, Niwattisaiwong $N$, Patarapanich $\mathrm{C}$, Tantisira $\mathrm{MH}$, Lawanprasert $\mathrm{S}$. In vitro inhibitory effects of asiaticoside and madecassoside on human cytochrome P450. Elsevier Toxicology in vitro. 2011; 25:890-6.

17. Tam TW, Akhtar H, Arnason JT, Cvijovic K, Boon H, Cameron DW, et al.Inhibition of human cytochrome P450 metabolism by blended herbal products and vitamins. J Pharm Pharmaceut Sci. 2011; 14:1-16.

18. Guannan Li, Huang K, Nikolic D, Richard B, Van Breemen. High-Throughput Cytochrome P450 Cocktail Inhibition assay for assessing drug-drug and DrugBotanical Interactions. Drug metabdispos. 2015;43:1670-8.

19. Wang JJ, Guo JJ, Zhan J, Bu HZ, Lin JH. An in-vitro cocktail assay for assessing compound-mediated inhibition of six major cytochrome P450 enzymes. JPharm Anal. 2014; 4:270-8.

20. Ashwini S, Anitha R. "Anti-hyperglycaemic activity of Caralluma fimbriata - An In vitro Approach", PharmacognMag. 2017; 13:S499-44.

21. Sarah S, Dhanraj G, Anitha R. Anxiety and aromatherapy- a review. Int J Pharm Bio Sci. 2016; 7:267-73.

22. Roy A, Geetha RV. In vitro $\alpha$ - Amylase and $\alpha$ - Glucosidase Inhibitory Activities of The Ethanolic extract of Dioscorea villosa Tubers, Int. J Pharma Bio Sci. 2013;4:49-54.

23. Ashwini S, Ezhilarasan D, Anitha R. Cytotoxic effect of Caralluma fimbriata against human colon cancer cells- in Pharmacogn J.2017; 9:204-7.

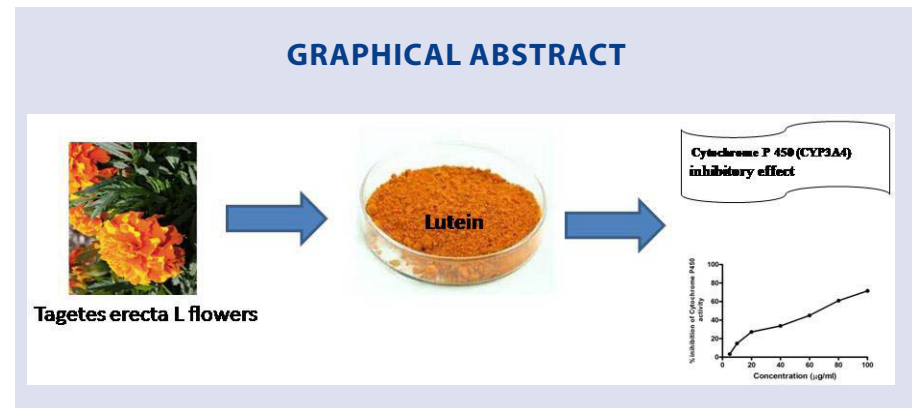

\section{SUMMARY}

- Lutein was extracted from the flowers of Tagetes erecta $L$ (Marigold) flowers family Compositae

- Lutein is chemically $3 R, 3^{\prime} R, 6^{\prime} R-\beta \varepsilon$-carotene-3, 3'-diol

- All the tested concentrations $(5-100 \mu \mathrm{g} / \mathrm{ml})$ of lutein showed dose - dependent manner inhibitory effect on Cytochrome P450 (CYP3A4) enzyme

- The IC $\mathrm{IC}_{50}$ value of lutein for CYP3A4 inhibitory activity was found to be $35.27 \mu \mathrm{g} /$ $\mathrm{ml}$.

- Results indicate possibilities of herb-drug interaction if this extract is co-administered with the prescribed drugs that are metabolized by CYP3A4

Cite this article: Meenapriya M, Anitha R, Lakshmi T. Effect of Lutein on Cytochrome CYP3A4 an in vitro study. Pharmacog J. 2018;10(6):1093-5 